\title{
Internal audit quality and resistance to pressure
}

\author{
Salem M. AL Fayi \\ Accounting Department, Faculty of Administration Science, \\ Najran University, Saudi Arabia
}

\begin{abstract}
Purpose - The work of internal auditors is relevant to their host entities' reporting processes; however, few researchers have examined how internal auditors' competency and objectivity affect their resistance to pressure from host entities regarding their reports. Thus, the main objective of this study is to examine the influence of internal audit functions' (IAF) quality factors on chief audit executives' (CAEs) ability not to modify internal audit report.
\end{abstract}

Design/methodology/approach - This study uses data from the Global Internal Audit Common Body of Knowledge to investigate the relationship between IAF quality and auditor resistance to pressure related to changes in internal audit reports. IAF quality is calculated using a composite measure comprising four IAF quality components. Auditors' resistance is measured using the extent to which internal auditors experienced a situation wherein they were directed to modify a valid audit finding in a report.

Findings - The analyses provide evidence that CAEs experience, certification, training and objectivity were all significantly associated with resistance to pressure. In other words, a greater quality of IAF leads to a greater ability to resist pressure to change their reports.

Research limitations/implications - Despite the statistically significant results that confirm the impact of IAF competence and objectivity on the resistance of CAEs to pressure, some other factors should be considered simultaneously in future research. In addition, the study sample contains 2,193 CAEs from different regions, environments, sectors and business areas. Focussing on a particular environment, sector or organisation size may generate different results.

Practical implications - The following practical implications are proposed: First, internal audit regulators will find this study helpful in formulating strategies for creating balanced relationships between CAEs and other authorities and users. Second, CAEs can be encouraged to undergo constant training and complete professional development (as required by the Institute of Internal Auditors [IIA] standard). Finally, it would be interesting to apply this study to a particular environment, sector and size.

Originality/value - This study builds on the limited research that investigates the relationship between IAFs' quality and the resistance of CAEs to pressure. It extends Calven's (2021) study that investigates the impact of adherence to the IIA's Core Principles on the likelihood of IAFs modifying valid audit findings. This study examines the influence of IAF quality factors on CAEs' ability not to modify internal audit report.

Keywords Codes of ethics, Integrity, Internal audit function quality, Internal audit report, Internal auditor resistance to pressure, Professional practice

Paper type Research paper

(C) Salem M. AL Fayi. Published in Journal of Money and Business. Published by Emerald Publishing Limited. This article is published under the Creative Commons Attribution (CC BY 4.0) licence. Anyone may reproduce, distribute, translate and create derivative works of this article (for both commercial and non-commercial purposes), subject to full attribution to the original publication and authors. The full terms of this licence may be seen at http://creativecommons.org/licences/by/4.0/legalcode.

Data availability statement: The Institute of Internal Auditors Research Foundation controls access to the Common Body of Knowledge (CBOK) survey data.

Funding statement: No funding was provided for this research.

Ethics approval statement: Approval to use the data set was received from the Institute of Internal Auditors Research Foundation and CBOK 2015 Global Internal Audit Practitioner Survey Committee.

Permission to reproduce material from other sources: No materials from other sources were used in this study.

Conflict of interest disclosure: there is no conflict of interest in this research.

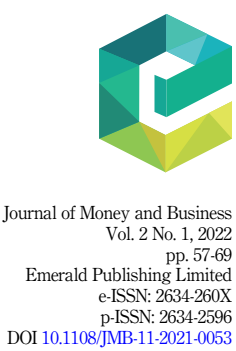

Received 1 December 2021

Revised 29 January 2022

Accepted 29 January 2022 
$\underset{2,1}{\mathrm{JMB}}$

\section{Introduction}

The Institute of Internal Auditors (IIA) considers the internal audit function (IAF) to be one of the pillars of an effective corporate governance model, along with the audit committee (AC) of the board of directors, the executive management and the external auditor (Gramling et al., 2004). The scope of internal auditors covers auditing and provides a variety of assurance and consulting services for companies (The Institute of Internal Auditors [IIA], n.d.). However, this dual role of controller and service provider may impair the quality of reporting. The argument underpinning the assumption is that internal auditors will be more willing to cooperate with management's wishes and requests, which may influence their reporting decision.

One aspect of such vulnerability is the threat to the auditor's independence that results from the weaker power exercised by the AC compared to the top managers (Roussy, 2015) or the conflict of interest between the two masters (Norman et al., 2010). For example, in a developed country such as Saudi Arabia, internal auditors believe they are not free to report fraud, wrongdoing or mistakes due to management pressure (Al-Twaijry et al., 2003). It has also been shown that a low level of independence from management influences the value and reliance of the work of IAF (A Fayi, 2021; Al-Twaijry et al., 2004).

The effect of internal auditing on the quality of financial and non-financial disclosure has been under consideration. For instance, Schneider (2010) analysed professional standards and research findings pertaining to external auditors' reliance on IAF. Statement Auditing Standard (SAS) No. 65 states that external auditors should evaluate the competence, objectivity and work of the IAF to make a reliance decision. Specifically, SAS No. 65 suggests that external auditors should assess the competence of the chief audit executive (CAE) using their professional experience, professional certifications and training. In addition, it suggests that external auditors should assess CAE objectivity using their reporting lines (American Institute of Certified Public Accountants [AICPA], 1997). This objectivity assessment is also relevant to IIA standards.

The IIA standards confirm that internal auditors should communicate risk and control information to the AC, board of directors, external auditors, senior management and other appropriate areas of the organisation. They "must possess the knowledge, skills, and other competencies needed to perform their individual responsibilities" (IIA, 2016, p. 6). They should be independent and objective to meet the governance-related expectations of the AC and management. Internal auditors' competence can be demonstrated through ' $a$ mixture of experience and theoretical learning' (IIA, 2016, p. 8), while objectivity is effectively achieved when the CAE reports functionally (e.g. on the approving charter, planning, execution and results of audit activities) to the highest authority in the organisation.

The value and credibility of internal auditors are guaranteed by their competency and objectivity. These two concepts have been extensively studied in the context of external auditing (e.g. Bame-Aldred et al., 2013). However, the new role of the IAF in corporate governance has piqued the interest of researchers in examining the impact of competency and objectivity on IAF quality (Abbott et al., 2015; Ege, 2015; Pizzini et al., 2015; Roussy and Brivot, 2016; Nalukenge et al., 2021). Interestingly, IAF is part of the corporate governance system while simultaneously providing consultancy services for the company. Thus, employees of the company would naturally question their objectivity in the discharge of their duties.

This study builds on the limited research that investigates the relationship between IAF quality and the resistance of CAEs to pressure. It extends Calven (2021) study that investigates the impact of adherence to the IIA's Core Principles on the likelihood of IAF modifying valid audit findings. This study examines the influence of IAF quality factors on CAEs' ability not to modify internal audit report. Data from the Institute of Internal Auditors Research Foundation (IIARF) for the fiscal year 2015 was used in order to test the hypothesis that composite measures of IAF quality are negatively associated with the measure of clients conceding to the pressure to modify a valid internal audit report. 
The measures of IAF quality used by external auditors suggested by the AICPA were applied in this study. Specifically, the measures included the number of years of experience in the field of internal auditing, the qualification of CAEs that are professionally certified (e.g. certified internal auditor [CIA], certified public accountant [CPA], etc.), the CAEs' formal training, and their reporting relation with high authority. In addition, for internal auditors' resistance to pressure, this study uses the extent of pressure when internal auditors experience a situation in which they have been directed to modify a valid internal audit report.

Finally, increased reliance on the IAF by others makes it imperative to seek a better understanding (Desai et al., 2010). Thus, this study investigates the influence of the quality of IAF on the perceived pressure of changing valid internal audit findings. Doing so contributes to research examining the impact of various components of CAEs' competency and objectivity on the pressure to change internal audit reports.

\section{Evaluation of internal audit quality}

In 2014, the AICPA issued SAS No. 128 using internal auditors' work (AICPA, 2014). SAS No. 128 helps the external auditor assess and evaluate the quality of the IAF. SAS No. 128 supersedes SAS No. 65 the auditors' consideration of the IAF in an audit of financial statements (AICPA, 1991), which superseded SAS No. 9 the effect of an IAF on the scope of the independent auditor's examination, issued in 1975 (AICPA, 1975; Schneider, 2010). The AICPA adopted SAS No. 128 to develop the role of internal auditing. They also aimed to provide more specific criteria for evaluating the competence and objectivity of the IAF.

The scope of SAS No. 128 addresses the external auditor's responsibilities if using the work of the IAF to obtain audit evidence and provide direct assistance. However, this section does not apply when the IAF activities are not relevant to the audit or if they do not meet the requirements for evaluating the quality of the IAF. Therefore, external auditors should evaluate the level of competence and objectivity of the IAF (AICPA, 2014). Competence of the IAF refers to "the attainment and maintenance of knowledge and skills of the function as a whole" (AICPA, 2020, p. 755). Objectivity refers to "the ability to perform tasks without allowing bias, conflict of interest, or undue influence of others to override professional judgments" (AICPA, 2020, p. 754). Competence and objectivity may be viewed as a continuum, but a high level of competence cannot compensate for lack of objectivity, and the opposite is true (Rodgers and Al Fayi, 2019).

\subsection{Evaluating chief audit executives' competence and objectivity}

The AICPA SAS No. 128 suggests that external auditors assess CAEs' competence using their professional experience, professional certifications and technical training. Experience refers to the number of years of experience in internal auditing. The qualification of internal auditors refers to the CAEs that are professionally certified (e.g. CIA, CPA, etc.). Finally, training refers to formal training (Schneider, 2010).

Additionally, AICPA SAS No. 128 suggests that external auditors assess CAE objectivity using their reporting lines (AICPA, 1997). According to the literature on external audit reliance decisions, the CAE should report to the highest authority to ensure the objectivity of internal auditors (Munro and Stewart, 2011; Rodgers and Al Fayi, 2019; Al Fayi, 2021). Thus, the IAF should not be accountable to management below the level of the board, as this weakens their assurance. A close relationship between the CAE and management can lead to career risk or management pressure on the CAE. Such relationships should be clearly defined to create good corporate governance and avoid negative consequences (Leung et al., 2011).

Internal auditors' competence can be demonstrated through " $a$ mixture of experience and theoretical learning" (IIA, 2016, p. 8). Objectivity is "an unbiased mental attitude that allows 
$\mathrm{JMB}$ 2,1

internal auditors to perform engagements in such a manner that they believe in their work product and that no quality compromises are made" (IIA, 2016, p. 3). Attribute standard 1110 organisational independence states "the chief audit executive must report to a level within the organisation that allows the internal audit activity to fulfil its responsibilities" (IIA, 2016, p. 4). Organisational independence is effectively achieved when the CAE functionally reports to the board.

According to IIA (n.d.), internal auditing is "an independent, objective assurance and consulting activity designed to add value and improve an organisation's operations. It helps an organisation accomplish its objectives by bringing a systematic, disciplined approach to evaluate and improve the effectiveness of risk management, control, and governance processes."

The definition of the IAF clarifies the importance of internal auditors' competence and objectivity rules. The importance of internal auditors' competence is related to their mission in risk management, control and governance processes that require a great deal of experience. In contrast, the importance of internal auditors' objectivity refers to exercising their duties related to assurance and consulting activities in an objective way. Objectivity is an impartial reasoning mind-set that results in an honest judgement. The CAEs should manage any threats to objectivity at the individual level, engagement and functional and organisational levels. Therefore, a CAE's primary or only reporting line should be the non-executive members of the board (Chambers and Odar, 2015). Unfortunately, the standards do not clearly state whether the internal auditor should report for all purposes to the board or the AC and do not stipulate that administrative reporting should be to the chief executive officer (CEO), not to the chief financial officer (Chambers, 2014).

According to The IIA (2009) "Code of Ethics", internal auditors should "exhibit the highest level of professional objectivity in gathering, evaluating, and communicating information about the activity or process being examined". Moreover, internal auditors should objectively consider all relevant facts and should not be influenced by their self-interest or receiving pressure from other parties during the internal auditing process. In this context, internal auditors should avoid all the activities and relationships that affect their honest views and professional judgement and report all the available information that would affect the quality of the internal audit report if not reported. Therefore, internal auditors shall spot threats to objectivity, estimate their extent and manage these threats.

The increased recognition of the IAF has a significant impact on reporting quality, as little research has studied this issue due to the difficulty of data collection. Previous studies have examined the impact of IAF quality on earnings management using archival data (Prawitt et al., 2008). Davidson et al. (2005) did not confirm that the existence of IAF lowers management earnings, and the effect of the quality of the IAF on financial reporting is more relevant than the effect of the presence of an IAF.

Previous experimental research has confirmed that efficient IAF improves a company's reporting quality and that internal auditors are able to deter opportunistic financial reporting, such as external auditors. In an experimental study, Asare et al. (2008) concluded that internal auditors assign more time when auditing a company where management is highly motivated to alter financial reporting. These experimental studies suggest that IAF increases reporting quality by preventing opportunistic management behaviour. It is reasonable to expect, however, that the degree of this deterrent effect will depend on the quality of the IAF, which is rooted in the IAF's competence and its independence from management.

Based on these arguments, it is expected that a high-quality IAF is associated with greater resistance to change findings pressure.

\section{Methodology and model specification}

The purpose of this study is to test whether IAF quality is negatively associated with CAEs by changing valid internal audit reports. Accordingly, this study develops a composite 
measure using the IIA guidelines. This measure is correlated with pressure to change the internal audit findings. In the following sections, a discussion of the data and study sample, measures of IAF quality and the pressure of valid internal audit report findings are presented.

\subsection{Data and sample}

To achieve the primary goal of this study, analyses were conducted using data from the Global Internal Audit Common Body of Knowledge-The CBOK 2015 Global Internal Audit Practitioner Survey (Institute of Internal Auditors Research Foundation [IIARF] 2015). The CBOK survey was developed and validated by the IIARF to benefit internal auditors, the internal auditing profession and the general public. Due to ethical considerations, the researcher requested access to data from the IIARF. After receiving approval from the CBOK committee members, the use of the CBOK survey was approved.

The CBOK survey was conducted in 166 countries/territories. It includes 14,518 practitioners representing different internal auditors at various levels amongst 150 chapters and 106 institutes. However, for the purpose of this research, only CAEs or equivalent responses from six regions were included in the statistical analysis (IIARF, 2015), and we were able to identify 2,193 CAEs without missing values or outliers.

\subsection{Variables measurement}

This study is guided by the measures used by external auditors when assessing internal audit quality to test the research proposition. In this context, external auditing standards highlight the concept of competence and objectivity in their definition of internal audit quality (AICPA, 1997). Therefore, this study uses four characteristics of CAEs to measure IAF quality (experience, certification, training and objectivity).

Figure 1 summarises the key aspects of the study. The survey questions measure the IAF quality in terms of the CAEs' experience, professional certification, training and objectivity, as well as the dependent variable question (CAEs' resistance to pressure).

Internal auditors should "possess the knowledge, skills, and other competencies needed to perform their individual responsibilities" (IIA, 2016, p. 6). Auditors' competence allows them to identify situations in which managers are motivated to act opportunistically and resist the pressure to change valid internal auditing reports. Moreover, managers are discouraged from asking for audit changes when they perceive the CAE as competent. Specifically, SAS No. 65 suggests that external auditors should assess CAE competence using their professional

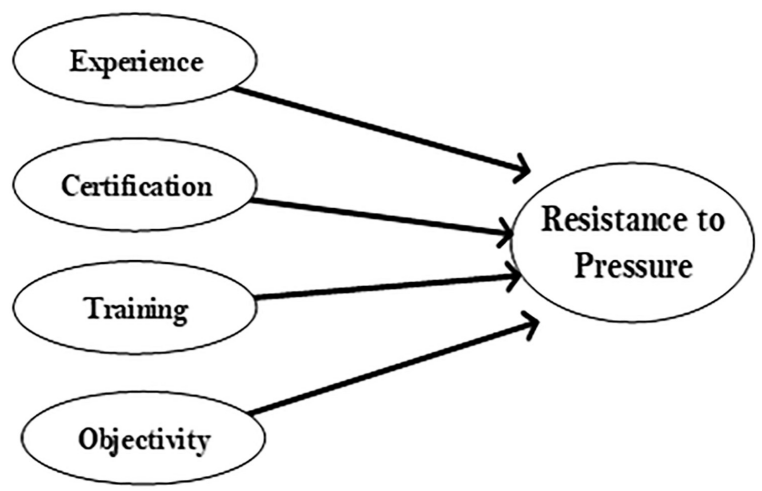

Internal audit quality

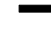


$\mathrm{JMB}$ 2,1

62

Table 1.

Descriptive statistics of Std. Deviation

the independent

variables

experience, professional certifications and training (AICPA, 1997). Therefore, three variables were used as proxies for competency factors: the CAEs' experience, professional certification and technical training. Experience refers to the number of years served by CAEs in the field of internal auditing. Certification refers to the qualification of the CAEs that are professionally certified (e.g. CIA, CPA, CMIIA, etc.). Training refers to formal training related to whether the CAEs have an area of technical specialisation for which they have had formal training or have spent most of their time working on formal training.

SAS No. 128 accepts that the external auditor should assess the CAE's objectivity (AICPA, 2014). Objectivity is expected to increase the quality of IAFs and increase their resistance. According to SAS No. 128 and relevant IIA standards, the primary organisational aspect of IAF objectivity revolves around the reporting status of the CAE. To proxy for objectivity, the reporting relationship was applied as a dummy variable, indicating whether the CAEs of the IAF report to a position of low authority $(\mathrm{CEO}=1)$ or a position of high authority (board, $\mathrm{AC}$ or general/legal counsel $=2$ ).

Table 1 shows the descriptive statistics for the independent variables, which confirm there are 2,193 valid respondents (CAEs) without missing values or outliers.

The dependent variable is related to the resistance of CAEs to pressure to change findings incidents. The "pressure to change findings" incidents will be measured by the following question: Have you experienced a situation where you were directed to suppress or significantly modify a valid internal audit finding or report? Table 2 presents the descriptive statistics of the dependent variables.

In this study, Tables 2 and 3 demonstrate that there is no need for further action related to the treatment of missing values, as there are 2,193 valid respondents without any missing

\begin{tabular}{|c|c|c|c|c|c|}
\hline & & Experience & Certificate & Training & Objectivity \\
\hline \multirow[t]{2}{*}{$N$} & Valid & 2193 & 2193 & 2193 & 2193 \\
\hline & Missing & 0 & 0 & 0 & 0 \\
\hline \multicolumn{2}{|c|}{ Mean } & 12.9991 & 1.55 & 1.71 & 1.80 \\
\hline \multicolumn{2}{|c|}{ Std. Deviation } & 8.84131 & 0.498 & 0.454 & 0.403 \\
\hline \multicolumn{2}{|c|}{ Minimum } & 0.00 & 1 & 1 & 1 \\
\hline \multicolumn{2}{|c|}{ Maximum } & 46.00 & 2 & 2 & 2 \\
\hline
\end{tabular}

Table 2.

Descriptive statistics of Valid the dependent variables

\begin{tabular}{llrrrr}
\hline & Frequency & Percent & Valid percent & Cumulative percent \\
\hline \multirow{2}{*}{ Valid } & Never & 1,529 & 69.7 & 69.7 & 69.7 \\
& Yes, at least once & 664 & 30.3 & 30.3 & 100.0 \\
& Total & 2,193 & 100.0 & 100.0 & \\
& & & & \\
\hline
\end{tabular}

Table 3.

Zscore

\begin{tabular}{lccr}
\hline & $N$ & Minimum & Maximum \\
\hline Zscore: Experience & 2193 & -1.44397 & 3.60610 \\
Zscore: Certificate & 2193 & -1.09918 & 0.90937 \\
Zscore: Training & 2193 & -1.55894 & 0.64118 \\
Zscore: Objectivity & 2193 & -1.97202 & 0.50687 \\
Zscore: Pressure & 2193 & -0.65485 & 1.52639 \\
Valid $N$ (list wise) & 2193 & & \\
\hline
\end{tabular}


values. In addition, this study used the commonly used cut-off of $\pm 4(p<0.001$, two-tailed test) (Tabachnick and Fidell, 2012). No outliers were observed (Table 3).

\subsection{Statistical techniques selection}

The dependent variable was categorical (dichotomous). Thus, multiple regression is not suitable because the dependent variable is not categorical. Therefore, the best option that can be applied to achieve the research objective is binary logistic regression. It is a statistical technique that allows researchers to assess how well independent variables predict or explain the categorical (dichotomous) dependent variable. It assesses the adequacy of the model's "goodness-of-fit" and provides an indication of the relative importance of each independent (predictor) variable (Pallant, 2020).

Logistic regression is highly sensitive to (1) a small sample, (2) multicollinearity and (3) outliers. However, the examination of the aforementioned assumptions proved that the sample was large enough to run a logistic regression (2,193CAEs). In addition, as discussed in the previous section, there is no outlier problem. Finally, Table 4 confirms that there is no multicollinearity problem, as the tolerance values for predictive variables are not less than 0.10 (i.e., tolerance value $>0.93$ ). This is also supported by the VIF value, which is 1.06 and lower for all four variables, which is well below the cut-off of 10 . Therefore, there is no violation of the multicollinearity assumption. These results are not surprising; given that the Pearson correlation coefficient shows no high correlations amongst the four independent variables (above 0.9) (see Correlations Table 5). In the following section, the results of the logistic regression are discussed.

\section{Logistic regression results}

Logistic regression aims to assess the impact of several factors on the likelihood that CAEs would report that they were directed to suppress or significantly modify a valid internal audit finding or report. The model is summarised as follows:

$$
\begin{aligned}
\text { Resistance to Pressure }= & b 0+b 1 \text { Experience }+b 2 \text { Certificate }+b 3 \text { Training } \\
& +b 4 \text { Objectivity }+\xi
\end{aligned}
$$

\begin{tabular}{lcr}
\hline & Tolerance & VIF \\
\hline Experience & 0.939 & 1.064 \\
Certification & 0.947 & 1.056 \\
Training & 0.998 & 1.002 \\
Objectivity & 0.987 & 1.013 \\
Note(s): a. Dependent Variable: Pressure & &
\end{tabular}

Note(s): a. Dependent Variable: Pressure
Internal audit quality

63

\begin{tabular}{lccccc}
\hline & Experience & Certificate & Training & Objectivity & Pressure \\
\hline Experience & 1 & $0.235^{* *}$ & -0.014 & $0.125^{* *}$ & $0.140^{* *}$ \\
Certificate & $0.225^{* *}$ & 1 & 0.027 & $0.060^{* *}$ & $0.074^{* *}$ \\
Training & $-0.024^{* *}$ & $0.027^{* *}$ & 1 & 0.010 & $0.043^{*}$ \\
Objectivity & $0.109^{* *}$ & $0.060^{* *}$ & 0.010 & 1 & $0.063^{* *}$ \\
Pressure & $0.132^{* *}$ & $0.074^{* *}$ & $0.043^{*}$ & $0.063^{* *}$ & 1
\end{tabular}

Note(s): **. Correlation is significant at the 0.01 level (two-tailed)

*. Correlation is significant at the 0.05 level (two-tailed)

Table 4. Collinearity statistics 

$\mathrm{JMB}$
2,1

64

According to the logistic regression formula, the model contains four independent variables to predict the pressure of CAEs to suppress or significantly modify a valid internal audit finding or report. The full model contains four statistically significant predictors, $x^{2}$ (5, $N=2,193)=51.960 p<0.001$, indicating that the model can distinguish between CAEs who are or are not under pressure.

The dependent variable encoding table tells us how SPSS has dealt with the coding of the included dependent variable, in this case, whether CAEs are under pressure (record 1 value) or not under pressure (record 0 value). The same applies to the categorical variables coding table, which presents independent variable coding and the frequency for each group (see Table 6).

Omnibus tests of model coefficients provide an overall indication of how well the model performs, over and above the results obtained for "Block 0", with none of the predictors entered into the model. This is referred to as the "goodness-of-fit" test. The significant value is the probability of obtaining the chi-square statistic (51.960) if there is, in fact, no effect of the covariate on the dependent variable. In addition, the degree of freedom was four, which included the number of independent variables. In this case, the significance value was very high, $0.000(p<0.0005)$.

The model summary shows that the addition of all the covariates improves the model from $2,637.547$ to 2,689.507 (e.g. 2,637.547 + 51.960). Logistic regression does not have an equivalent to the $R$-squared, and what the reader can see in Cox and Snell's $R$-Square and Nagelkerke $R$-square are pseudo $R$-squares. The Cox and Snell $R$-square and Nagelkerke $R$ square values provide an indication of the amount of variation in the dependent variable explained by the model (from a minimum value of zero to a maximum of approximately 1 ). These are described as pseudo $R$-square statistics rather than the true $R$-square values provided in the multiple regression outputs. In this case, the two values are 0.024 and 0.033 , suggesting that between 2.4 and 3.3 of the variability is explained by this set of variables.

The results shown are in support with our model as being worthwhile. The HosmerLemeshow test is the most reliable test of model fit available in SPSS. This is interpreted very differently from the omnibus test discussed above. For the Hosmer-Lemeshow goodness-offit test, a good fit is indicated by a significant value higher than 0.05 . In this case, the chisquare value for the Hosmer-Lemeshow test is 7.445, with a significant level of $0.489>0.05$. Therefore, these results support this model.

A significant value lower than 0.05 , indicates that variables contribute significantly to the predictive ability of the model. Table 7 shows that internal audit quality variables significantly contribute to the model to predict the CAEs' resistance to pressure to change findings or reports. The importance of each internal audit quality variable is presented in the Wald test (see Figure 2).

Positive $B$ values indicate that an increase in the independent variable score will increase the probability of the case recording a score of zero in the dependent variable. In this case, better internal audit quality will lead to increased resistance to change findings or reports.

Table 6. Categorical variables coding

\begin{tabular}{llrc}
\hline & & Frequency & $\begin{array}{c}\text { Parameter coding } \\
\text { (1) }\end{array}$ \\
\hline Objectivity & Reporting to CEO & 448 & 0.000 \\
& Reporting to AC, board, general or legal counsel & 1745 & 1.000 \\
Training & No & 636 & 0.000 \\
& Yes & 1557 & 1.000 \\
Certification & No & 991 & 0.000 \\
& Yes & 1202 & 1.000 \\
& & &
\end{tabular}


The odds ratios for each predictor variable are presented in the Exp (B) column. The odds ratio represents "the change in odds of being in one of the categories of outcome when the value of a predictor increases by one unit" (Tabachnick and Fidell, 2012).

In this case, CAEs with more years of experience, qualifications and training have higher odds of resistance to pressure. In other words, CAEs with higher experience are more likely to have higher resistance to pressure by more than one time than those with less experienced CAEs. Qualified and trained CAEs will also have higher resistance to pressure by more than 1.2 times to unqualified and untrained CAEs. However, it is clear that reporting to high authority can lead to better relationships between the CAEs and the organisation's highest authority, which makes the CAEs have greater resistance to pressure to change findings. Objectivity variables record the highest odds by more than 1.3 times better resistance when the CAEs report to high authority rather than low authority (see Exp [B] in Table 7).

\section{Discussion and conclusion}

The study's findings show a statistically significant relationship $(\phi<0.05)$ between IAF quality factors and CAEs' resistance to pressure. The findings supported the proposition formulated by the researcher as a positive association was found between the investigated variables. In other words, a greater quality of IAF leads to a greater ability to resist pressure to change their reports. Similar results were found between IAF quality and external auditors' reliance on internal auditors' work. In addition, Johl et al. (2013) and Al Fayi (2021) showed that a positive relationship exists between IAF quality and IAF fund sufficiency. In addition, Mazza and Azzali (2015) found a negative association between internal auditors' independence, competence and internal control deficiencies. Finally, Gros et al. (2017) found a positive association between IAF quality, financial reporting quality and audit

\begin{tabular}{|c|c|c|c|c|c|c|c|}
\hline & & B & SE & Wald & Df & Sig & $\operatorname{Exp}(B)$ \\
\hline \multirow{5}{*}{ Step $1^{\mathrm{a}}$} & Experience1 & 0.029 & 0.005 & 28.426 & 1 & 0.000 & 1.029 \\
\hline & Certificate1(1) & 0.196 & 0.098 & 4.047 & 1 & 0.044 & 1.217 \\
\hline & Training1(1) & 0.224 & 0.106 & 4.462 & 1 & 0.035 & 1.251 \\
\hline & Objectivity1(1) & 0.279 & 0.123 & 5.160 & 1 & 0.023 & 1.322 \\
\hline & Constant & -1.717 & 0.155 & 122.334 & 1 & 0.000 & 0.180 \\
\hline
\end{tabular}

Note(s): a. Variable(s) entered on step 1: Experience1, Certificate1, Training1 and Objectivity1
Internal audit quality
Table 7. Variables in the equation

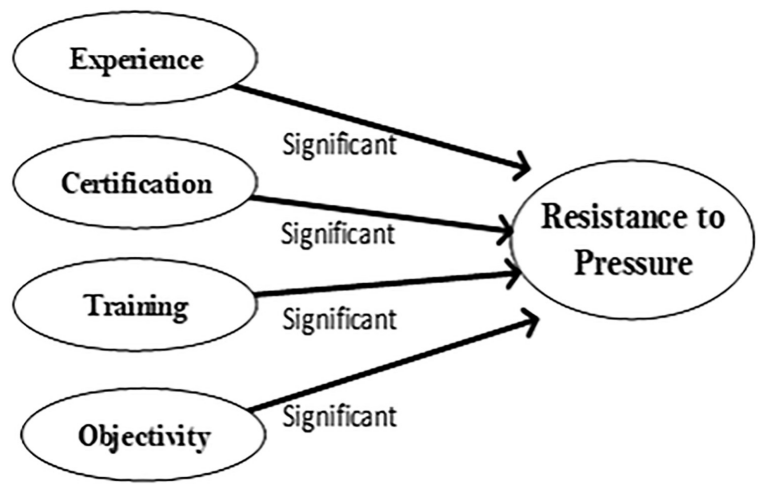

Figure 2.

The significance pathways 
$\mathrm{JMB}$ 2,1

efficiency. However, this study is an original effort to investigate the influence of IAF competence and objectivity on the quality of IAF reports by examining the ability of CAEs to resist pressure to change findings incidents.

Previous studies have found IAF competence and independence to be definite indications of IAF quality. When present, these phenomena improve CAEs' resistance to pressure, consequently improving IAF reports. The factors of IAF competence include experience, certification and training. The results of this study confirm the significant relationships between the aforementioned variables and the resistance of CAEs to pressure.

In many studies, job-relevant experience, measured by the number of years, is used as a proxy for expertise. Individuals with many years of experience are considered "experts", in contrast to others with little experience who are labelled "novices". This is rational, as no one can function as an "expert" without the necessary competence. However, despite the uncertainty about experience as a predictor of the degree of expertise, it reflects seniority as a result of the positive association between experience and performance (Shanteau et al., 2002).

The qualification of an internal auditor refers to the CAEs that are professionally certified (e.g. CIA, CPA, etc.). Certified CAEs should provide users more comfort regarding internal audit integrity and quality (Schneider, 2010). Internal auditors must have all the requisite skills to carry out duties associated with the International Standards for the Professional Practice of Internal Auditing. Therefore, qualified CAEs can have more power to plan their work and identify their needs. Simultaneously, training is measured by the CAEs' formal training. CAEs need to have the skills and competencies necessary to achieve individual duties, including professional care and proficiency. They can only attain these skills by undertaking proper training and development programmes (Endaya and Hanefah, 2016).

The IAF is distinguished from many other internal assurance providers by virtue of the required compliance with professional standards and a code of ethics that demands independence and objectivity. Consequently, the importance of internal auditors' independence and objectivity continues to increase with the development of the business environment (e.g. the need for greater transparency, more disclosures and corporate governance) (IIA, 2016).

The results of this study suggest that the advantages gained from IAF competence and objectivity can help CAEs to have an independent opinion and can deliver their reports freely and independently without any pressure to change findings. To investigate this proposition, the answers for 2193 CAEs from six different regions were examined. Study findings should be a matter for regulators, external auditors and researchers. In this study, the association between CAEs' resistance to pressure and IAF competence and objectivity is explored, and the study confirms the advantages of IAF competence and objectivity in terms of improved resistance to pressure, resulting in better IAF reports.

\subsection{Limitations and agenda for further research}

In conclusion, it should be pointed out that the study, as reported, is subject to certain limitations. Despite the statistically significant results that confirm the impact of IAF competence and objectivity on the resistance of CAEs to pressure, some other factors should be considered simultaneously in future research. For instance, Alzeban (2018) investigated the influence of the CEO's involvement in approving and appointing the CAE on the quality of IAF reports. He found that the benefits of an independent and competent IAF are only evident when the CEO is not involved in the appointment since management can override internal audit controls. In addition, the study sample contains 2,193 CAEs from different regions, environments, sectors and business areas. Focussing on a particular environment, sector or organisation size may generate different results. This research can be considered a robust basis for future research, as we know very little of such context and issues. 


\subsection{Practical implications}

The current research findings offer insight into the connection between IAF quality and CAEs' resistance to pressure. The implications of this study could help to find ways to improve the quality of IAFs in general and their reports in particular. The following practical implications are proposed: First, internal audit regulators will find this study helpful in formulating strategies for creating balanced relationships between CAEs and other authorities and users. Second, CAEs can be encouraged to undergo constant training and complete professional development (as required by the IIA standard "Internal auditors must enhance their knowledge, skills, and other competencies through continuing professional development"; IIA, 2016, p. 7). Finally, it would be interesting to apply this study to a particular environment, sector and size. Confirmation and generalisation of the results with the respective data from a particular region will be suggested. I hope that the present research will become a point of reference and encourage future research.

\section{References}

Abbott, L.J., Daugherty, B., Parker, S. and Peters, G.F. (2015), "Internal audit quality and financial reporting quality: the joint importance of independence and competence", Journal of Accounting Research, Vol. 54 No. 1, pp. 3-40, doi: 10.1111/1475-679X.12099.

Al Fayi, S.M. (2021), "Factors influencing internal audit fund sufficiency", The Scientific Journal of King Faisal University - Humanities and Management Sciences, Vol. 2 No. 22, pp. 325-332, doi: 10.37575/h/mng/210023.

Al-Twaijry, A.A.M., Brierley, J.A. and Gwilliam, D.R. (2003), "The development of internal audit in Saudi Arabia: an institutional theory perspective”, Critical Perspectives on Accounting, Vol. 14 No. 5, pp. 507-531, doi: 10.1016/S1045-2354(02)00158-2.

Al-Twaijry, A.A.M., Brierley, J.A. and Gwilliam, D.R. (2004), "An examination of the relationship between internal and external audit in the Saudi Arabian corporate sector", Managerial Auditing Journal, Vol. 19 No. 7, pp. 929-944, doi: 10.1108/02686900410549448.

Alzeban, A. (2018), "CEO involvement in selecting CAE, internal audit competency and independence, and financial reporting quality", Journal of Business Economics and Management, Vol. 19 No. 3, pp. 456-473, doi: 10.3846/jbem.2018.6264.

American Institute of Certified Public Accountants (AICPA) (1975), Statement on Auditing Standards No. 9. The Effect of an Internal Audit Function on the Scope of the Independent Auditor's Examination, American Institue of Certified Public Accountants, New York.

American Institute of Certified Public Accountants (AICPA) (1991), Statement on Auditing Standards No. 65. The Auditors' Consideration of the Internal Audit Function in an Audit of Financial Statements, American Institue of Certified Public Accountants, New York.

American Institute of Certified Public Accountants (1997), AICPA Professional Standards. Statement on Auditing Standards No. 128, Using the Work of Internal Auditors, available at: https://us. aicpa.org/research/standards/auditattest/clarifiedsas (accessed 11 February 2022).

American Institute of Certified Public Accountants (AICPA) (2014), Statement on Auditing Standards No. 128, Using the Work of Internal Auditors, AICPA, available at: https:/us.aicpa.org/content/ dam/aicpa/research/standards/auditattest/downloadabledocuments/sas-128-summary.pdf (accessed 13 June 2021).

American Institute of Certified Public Accountants (AICPA) (2020), Using the Work of Internal Auditors, AICPA, available at: https://www.aicpa.org/research/standards/auditattest/ downloadabledocuments/au-c-00610.pdf (accessed 1 May 2021).

Asare, S., Davidson, R. and Gramling, A. (2008), "Internal auditors' evaluation of fraud factors in planning an audit: the importance of audit committee quality and management incentives", International Journal of Auditing, Vol. 12 No. 3, pp. 181-203, doi: 10.1111/j.1099-1123.2008. 00379.x. 
$\mathrm{JMB}$ 2,1
Bame-Aldred, C.W., Brandon, D.M., Messier, W.F. Jr, Rittenberg, L.E. and Stefaniak, C.M. (2013), “A summary of research on external auditor reliance on the internal audit function", Auditing: A Journal of Practice \& Theory, Vol. 32 No. 1, pp. 251-286, doi: 10.2139/ssrn.2035087.

Calven, C.G. (2021), "Adherence to the internal audit Core Principles and threats to internal audit function effectiveness", Auditing: A Journal of Practice and Theory, Vol. 40 No. 4, pp. 79-98, doi: 10.2308/AJPT-19-072.

Chambers, A.D. (2014), "Guidance on internal audit's interface with regulators", Managerial Auditing Journal, Vol. 29 No. 3, pp. 268-283, doi: 10.1108/MAJ-08-2013-0927.

Chambers, A.D. and Odar, M. (2015), "A new vision for internal audit”, Managerial Auditing Journal, Vol. 30 No. 1, pp. 34-54, doi: 10.1108/MAJ-08-2014-1073.

Davidson, R., Goodwin-Stewart, J. and Kent, P. (2005), "Internal governance structures and earnings management", Accounting and Finance, Vol. 45 No. 2, pp. 241-267, doi: 10.1111/j.1467-629x.2004. 00132.x.

Desai, V., Roberts, R.W. and Srivastava, R. (2010), "An analytical model for external auditor evaluation of the internal audit function using belief functions", Contemporary Accounting Research, Vol. 27 No. 2, p. 346, doi: 10.1111/j.1911-3846.2010.01023_4.x.

Ege, M.S. (2015), "Does internal audit function quality deter management misconduct?", Accounting Review, Vol. 90 No. 2, pp. 495-527, doi: 10.2308/accr-50871.

Endaya, K.A. and Hanefah, M.M. (2016), "Internal auditor characteristics, internal audit effectiveness, and moderating effect of senior management", Journal of Economics and Administrative Sciences, Vol. 22 No. 2, pp. 160-176.

Gramling, A.A., Maletta, M.J., Schneider, A. and Church, B.K. (2004), "The role of the internal audit function in corporate governance: a synthesis of extant internal auditing literature and directions for future research", Journal of Accounting Literature, Vol. 23, pp. 194-244.

Gros, M., Koch, S. and Wallek, C. (2017), "Internal audit function quality and financial reporting: results of a survey on German listed companies", Journal of Management and Governance, Vol. 21, pp. 291-329, doi: 10.1007/s10997-016-9342-8.

Institute of Internal Auditors (IIA) (2009), “Code of ethics”, available at: https:/global.theiia.org/ standards-guidance/mandatory-guidance/Pages/Code-of-Ethics.aspx.

Institute of Internal Auditors (IIA) (2016), International Standards for the Professional Practice of Internal Auditing. 1110-1 Organizational Independence, IIA Global, available at: https://na. theiia.org/standards-guidance/Public\%20Documents/IPPF-Standards-2017.pdf.

Institute of Internal Auditors (IIA) (n.d.), "Definition of internal auditing", available at: https://na.theiia. org/standards-guidance/mandatory-guidance/Pages/Definition-of-Internal-Auditing.aspx.

Institute of Internal Auditors Research Foundation (IIARF) (2015), The CBOK 2015 Global Internal Audit Practitioner Survey Questions, IIA Global, available at: https:/global.theiia.org/iiarf/ Public\%20Documents/CBOK-2015-Practitioner-Survey-Question-List.pdf (accessed 10 April 2021).

Johl, S.K., Johl, S.K., Subramaniam, N. and Cooper, B. (2013), "Internal audit function, board quality and financial reporting quality: evidence from Malaysia", Managerial Auditing Journal, Vol. 28 No. 9, pp. 780-814, doi: 10.1108/MAJ-06-2013-0886.

Leung, P., Cooper, B.J. and Perera, L. (2011), “Accountability structures and management relationships of internal audit”, Managerial Auditing Journal, Vol. 26 No. 9, pp. 794-816, doi: 10.1108/ 02686901111171457.

Mazza, T. and Azzali, S. (2015), "Effects of internal audit quality on the severity and persistence of controls deficiencies", International Journal of Auditing, Vol. 19 No. 3, pp. 148-165, doi: 10.1111/ ijau.12044.

Munro, L. and Stewart, J. (2011), "External auditors' reliance on internal auditing: further evidence", Managerial Auditing Journal, Vol. 26 No. 6, pp. 464-481, doi: 10.1108/02686901111142530. 
Nalukenge, I., Kaawaase, T.K., Bananuka, J. and Ogwal, P.F. (2021), "Internal audit quality, punitive measures and accountability in Ugandan statutory corporations", Journal of Economic and Administrative Sciences, available at: https://www.emerald.com/insight/content/doi/10.1108/ JEAS-05-2020-0084/full/html.

Norman, C.S., Rose, A.M. and Rose, J.M. (2010), "Internal audit reporting lines, fraud risk decomposition, and assessments of fraud risk", Accounting Organizations and Society, Vol. 35 No. 5, pp. 546-557, doi: 10.1016/j.aos.2009.12.003.

Pallant, J. (2020), SPSS Survival Manual: A Step by Step Guide to Data Analysis Using IBM SPSS, 7th ed., Routledge, London.

Pizzini, M., Lin, S. and Ziegenfuss, D.E. (2015), "The impact of internal audit function quality and contribution on audit delay", Auditing: A Journal of Practice and Theory, Vol. 34 No. 1, pp. 25-58, doi: 10.2308/ajpt-50848.

Prawitt, D., Smith, J. and Wood, D. (2008), "Internal audit quality and earnings management", The Accounting Review, Vol. 84 No. 4, pp. 1255-1280, doi: 10.2308/accr.2009.84.4.1255.

Rodgers, W. and Al Fayi, S. (2019), "Ethical pathways of internal audit reporting lines", Accounting Forum, Vol. 43 No. 2, pp. 220-245, doi: 10.1080/01559982.2019.1605871.

Roussy, M. (2015), "Welcome to the day-to-day of internal auditors: how do they cope with conflicts?", Auditing: A Journal of Practice and Theory, Vol. 34 No. 2, pp. 237-264, doi: 10.2308/ajpt-50904.

Roussy, M. and Brivot, M. (2016), "Internal audit quality: a polysemous notion?", Accounting Auditing and Accountability Journal, Vol. 29 No. 5, pp. 714-738, doi: 10.1108/AAAJ-10-2014-1843.

Schneider, A. (2010), "Analysis of professional standards and research findings to develop decision aids for reliance on internal auditing", Research in Accounting Regulation, Vol. 22 No. 2, pp. 96-106, doi: 10.1016/j.racreg.2010.07.004.

Shanteau, J., Weiss, D.J., Thomas, R.P. and Pounds, J.C. (2002), "Performance-based assessment of expertise: how to decide if someone is an expert or not", European Journal of Operational Research, Vol. 136 No. 2, pp. 253-263.

Tabachnick, B.G. and Fidell, L.S. (2012), Using Multivariate Statistics, 6th ed., Pearson, Northridge.

\section{About the author}

Dr Salem M. AL Fayi is a Hull Business School graduate, a Saudi assistant professor, a dean of the Faculty of Business Science, Najran University, a member of the Institute of Internal Auditors, a director of the spending efficiency team at Najran University during 2019-2020 and a consultant of internal audit and financial accounting. He is the Chief Executive of Argam Office for Accounting Consulting and Service. Salem M. AL Fayi can be contacted at: salem.ksa@gmail.com

For instructions on how to order reprints of this article, please visit our website:

www.emeraldgrouppublishing.com/licensing/reprints.htm

Or contact us for further details: permissions@emeraldinsight.com 